\title{
Modeling of PollutionTransport for the Integrated Environmental Monitoring Based on the Adjoint Equations
}

\author{
Yu. N. Ryabtsev, M. V. Tsyganova* \\ Marine Hydrophysical Institute of RAS, Sevastopol, Russian Federation \\ *m.tsyganova@mhi-ras.ru
}

Purpose. The aim of the present paper is to solve the problem of choosing the localities in the Sevastopol Bay for optimal placing the pollution sources using the adjoint equations of the admixture transfer.

Methods and Results. The embankments in the city center, the Artilleriyskaya Bay and the city beach zone are chosen as the nature protection areas. Solution of the adjoint equation of the passive admixture transport yields the influence function that permits to reveal the areas on the coast, where, in case the pollution sources are placed there, the sanitary standards will be violated, and, at the existing structure of currents, these nature protection zones will suffer significant damage. To make sure that the adjoint equation is solved correctly, the direct problem can be solved for various locations of the impurity sources. Solution of the adjoint equation makes it possible to obtain information on the impurity amount in the preset nature protection zones during the preset time period at an arbitrary location of the impurity source. The currents velocities are calculated by the linear three-dimensional barotropic model for the steady wind currents.

Conclusions. The numerical modeling results revealed the regions, where placing of the pollution sources would violate sanitary standards in the nature protection zones under study. The experiments showed that the north and east winds were the most dangerous. Hence industrial facilities, storm and sewage discharges having been placed at the Northern side of the Sevastopol Bay, can be extremely harmful for the ecological state of the regions under consideration. At the east and southeast winds, the industrial activity products in the Yuzhnaya Bay constitute a basic source of contamination. At the south winds, the most dangerous situation occurs in case the pollution sources are placed at the coast of the recreational zone of the city.

Keywords: numerical modeling, coastal zone, adjoint equation, contamination transport, Sevastopol Bay.

Acknowledgements: the work was carried out within the framework of the state task for FSBSI FRC MHI on theme No. 0827-2019-0004 "Complex interdisciplinary studies of oceanological processes conditioning functioning and evolution of the ecosystems of the Black and Azov seas' coastal zones", and was funded by RFBR and Sevastopol, project number 20-45-920019 "Interdisciplinary investigation of physical and geographical parameters of urban sewer system in the semienclosed estuarine bay with the high anthropogenic load and their link to ecological and recreational state".

For citation: Ryabtsev, Yu.N. and Tsyganova, M.V., 2020. Modeling of Pollution Transport for the Integrated Environmental Monitoring Based on the Adjoint Equations. Physical Oceanography, [e-journal] 27(2), pp. 197-209. doi: 10.22449/1573-160X-2020-2-197-209

DOI: $10.22449 / 1573-160 X-2020-2-197-209$

(C) Yu. N. Ryabtsev, M. V. Tsyganova, 2020

(C) Physical Oceanography, 2020

\section{Introduction}

The reconstruction of the industrial potential of Sevastopol in recent years has caused an increase in anthropogenic impact on the coastal zone of the region. Industrial development of the shelf is at a fast pace, economic complexes are developing in the coastal waters, the recreational and bio-production potentials are being intensively used, and the seafood production is being intensively developing. 
Due to the recreational development of Sevastopol, the presence of nature conservation facilities such as dolphinariums and mariculture development zones, there is a need to increase the requirements for compliance with sanitary standards in the region. Therefore, special attention is paid to the study of the ecological state of the Sevastopol Bay [1-7].

During the construction of industrial facilities in the coastal zone, the task of their rational allocation to minimize possible damage from their activities appears. To solve this problem Academician Guriy I. Marchuk proposed a method in which the adjoint equations of contamination transport and diffusion are used (the adjoint problem) [8]. This method is often used in oceanology [9-13]. In a whole series of studies, the contamination transport in the Azov Sea is studied using adjoint equations [14-16].

The present paper is aimed to solve the problem of choosing the optimal location of pollution sources in the Sevastopol Bay using the adjoint equations of contamination transport. As a result of solving the adjoint problem, the information on the contamination amount in a given nature protection zone in a certain time period with an arbitrary location of the contamination source is obtained. A linear barotropic model of steady wind currents is used to calculate current velocities. Based on the results of numerical modeling, the regions where the location of contamination sources will lead to a violation of sanitary standards in the considered conservation zone are identified.

\section{Methods and Results}

Direct problem. The contamination transport equation, according to [17], is written as follows:

$$
\frac{\partial C}{\partial t}+\frac{\partial(u C)}{\partial x}+\frac{\partial(v C)}{\partial y}+\frac{\partial(W C)}{\partial z}-\frac{\partial}{\partial z}\left(\kappa \frac{\partial C}{\partial z}\right)-\mu \Delta C=F,
$$

where $x, y, z$ are the coordinate axes ( $z$ axis is down-directed); $t$ is the time; $C$ is the contamination concentration; $u, v, w$ are the current velocity components; $\mathbf{v}=\{u, v, w\}$ is the current velocity vector; $W=w+w^{*} ; w^{*}-$ actual contamination speed; $\kappa, \mu$-are the coefficients of vertical and horizontal diffusion; $F(x, y, z, t)$ is the source of contamination.

At the sea surface $\left(\Sigma_{0}\right)$, bottom $\left(\Sigma_{H}\right)$ and lateral surface $(S)$ boundary conditions are set for the total (advective and diffusive) contamination flow. Given the property of transportability, it can be written:

$$
\begin{array}{ll}
\text { when } z=0 & -\kappa \frac{\partial C}{\partial z}+W C=0, \quad w=0, \\
\text { when } z=H(x, y) & -\kappa \frac{\partial C}{\partial n}+U_{\mathrm{n}} C=0, \quad w-\mathrm{u} \frac{\partial H}{\partial x}-v \frac{\partial H}{\partial y}=0,
\end{array}
$$


where $H(x, y)$ is the sea depth in the point with the coordinates $(x, y) ; U_{\mathrm{n}}-\mathbf{U}=\{u$, $v, W\}$ vector component normal to the surface; $\frac{\partial C}{\partial n}$ is the normal derivative to the boundary.

Further, the condition for concentration in (3) is replaced with an approximate one:

$$
-\kappa \frac{\partial C}{\partial z}+w^{*} C=0
$$

On the side surface $S$, the boundary conditions are written in the following form

$$
-\mu \frac{\partial C}{\partial n}+u_{\mathrm{n}} C=u_{\mathrm{n}}^{+} C
$$

where $u_{\mathrm{n}}$ - is the velocity component normal to the boundary; $u_{\mathrm{n}}^{+}$is the flow velocity.

On the solid lateral boundary, the normal component of the horizontal velocity vector is equal to zero.

It is assumed that at the initial moment of time there is no contamination, that is, $C_{0}=0$. If the contamination concentration $C$ is measured in $\mathrm{g} / \mathrm{cm}^{3}$, then the dimension of the source function $F$ will be measured in $\mathrm{g} / \mathrm{cm}^{3} \cdot \mathrm{s}$.

Adjoint problem. To obtain the equation adjoint to equation (1), following [17], the equation (1) is multiplied by some function $C^{*}$ and integrated over time $t \in[0, T]$ and over the entire volume $G$ of the given reservoir. After the transformations we obtain:

$$
\begin{aligned}
& \int_{0}^{T} d t \int_{G} C\left(-\frac{\partial C^{*}}{\partial t}-\operatorname{div}\left(U C^{*}\right)-\frac{\partial}{\partial z}\left(\kappa \frac{\partial C^{*}}{\partial z}\right)-\mu \Delta C^{*}\right) d G= \\
& =\int_{0}^{T} d t \int_{G} C^{*} F d G-\int_{G} C_{T} C_{T}^{*} d G+\int_{G} C_{0} C_{0}^{*} d G-\int_{0}^{T} d t \int_{S} v_{\mathrm{n}} C^{*} C d \Sigma- \\
& -\int_{0}^{T} d t \int_{\Sigma_{0}} \kappa\left(C^{*} \frac{\partial C}{\partial z}-C \frac{\partial C^{*}}{\partial z}\right) d \Sigma+\int_{0}^{T} d t \int_{\Sigma_{\mathrm{H}}} \kappa\left(C^{*} \frac{\partial C}{\partial z}-C \frac{\partial C^{*}}{\partial z}\right) d \Sigma+ \\
& +\mu \int_{0}^{T} d t \int_{S}\left(C^{*} \frac{\partial C}{\partial n}-C \frac{\partial C^{*}}{\partial n}\right) d S-\int_{0}^{T} d t \int_{\Sigma_{\mathrm{H}}} w^{*} C C^{*} d \Sigma+\int_{0}^{T} d t \int_{\Sigma_{0}} w^{*} C C^{*} d \Sigma,
\end{aligned}
$$

where $v_{\mathrm{n}}$ is normal to the boundary component of the current velocity vector. The integrand on the left side of equation (6) is set equal to some function $p(x, y$, $z, t$ ). The equation for the function $C^{*}$ adjoint to equation (1) is obtained, i.e.

$$
-\frac{\partial C^{*}}{\partial t}-\operatorname{div}\left(U C^{*}\right)-\frac{\partial}{\partial z}\left(\kappa \frac{\partial C^{*}}{\partial z}\right)-\mu \Delta C^{*}=p .
$$


The left side of equation (6) is a functional

$$
J=\int_{0}^{T} d t \int_{G} p C d G
$$

which is calculated after solving the direct problem. For a given function $p$, the functional takes the form $J=J(C)$.

For the corresponding initial and boundary conditions in equation (7), the same functional (the right side of equation (6)) can also be calculated after solving the adjoint problem. In other words, the duality principle takes place:

$$
J(C)=J\left(C^{*}\right) \text {. }
$$

The "initial" condition for $C^{*}$ has the following form:

when $t=T \quad C_{T}^{*}=0$.

For equation (7), the boundary conditions are obtained, following [17]:

$$
\begin{array}{ll}
\text { when } z=0 & \kappa \frac{\partial C^{*}}{\partial z}=0, \\
\text { when } z=H(x, y) & \kappa \frac{\partial C^{*}}{\partial z}=0,
\end{array}
$$

for the lateral surface $\mu \frac{\partial C^{*}}{\partial n}+u_{\mathrm{n}} C^{*}=u_{\mathrm{n}}^{-} C^{*}$,

where $u_{\mathrm{n}}^{-}$- the inflow velocity in the region.

The equation (7) is reduced to a parabolic equation by changing the variable $t_{1}=T-t, t_{1} \in[0, T]$ and is written in divergent form:

$$
\frac{\partial C^{*}}{\partial t_{1}}-\frac{\partial}{\partial x}\left(u C^{*}+\mu \frac{\partial C^{*}}{\partial x}\right)-\frac{\partial}{\partial y}\left(\mathrm{v} C^{*}+\mu \frac{\partial C^{*}}{\partial y}\right)-\frac{\partial}{\partial z}\left[\left(w+w^{*}\right) C^{*}+\kappa \frac{\partial C^{*}}{\partial z}\right]=p .
$$

Accordingly, the initial condition (10) takes the following form:

when $t_{1}=0$

$$
C^{*}=0 .
$$

Note that the functional $J$ can have a different physical interpretation depending on the choice of function $p(x, y, z, t)$.

A restriction on sanitary conditions, i.e. the functional restriction fulfillment is required, is introduced:

$$
J \leq J_{\text {cr, }}
$$

where $J_{\text {cr }}$ is the critical value of the functional associated with the sanitary norm for a given environmental area.

Taking into account the sanitary criterion, the choice of a possible pollution source position involves the use of two approaches. In the first approach, a number of direct problems are solved with enumerating various locations of the pollution source and the optimal placement variant is selected based on criterion (15). 
In the second one, a one-time solution of the adjoint problem is proposed for a priori functions $p$ and $F$, which seems more efficient improved.

Numerical experiment. Consider the associated problem of the passive admixture propagation in the Sevastopol Bay zone. The calculations were carried out in the area shown in Fig. 1, $a$.

The embankments of the city center, the Artilleriyskaya Bay and the city beach area were selected as a nature protection object (zone). The area (approximately 100 m coastal zone) in Fig. 1, b is indicated by a "comb", contours of the bottom topography are drawn through $5 \mathrm{~m}$.
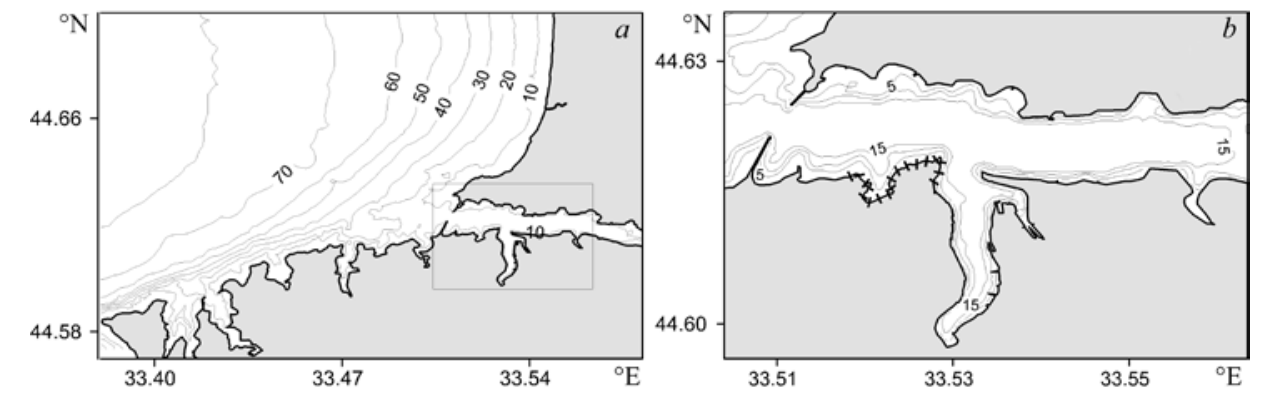

F i g. 1. Position of the calculational area $(a)$, bottom relief in the calculational area and location of the nature protection zone $(b)$

Solving the adjoint problem of passive admixture transfer, an influence function is obtained. It permits to identify coastal areas where the location of pollution sources can cause damage to the nature protection zone for a given current structure. Solving the direct problem for various positions of the contamination sources, we can verify that the results of solving the direct and adjoint problems are consistent.

The source function $F$ is defined as

$$
F=Q \delta(x-\xi) \delta(y-\eta) \delta(z-\zeta),
$$

where $(\xi, \eta, \zeta)$ are the contamination source position coordinates; $Q=$ const $(\mathrm{g} / \mathrm{s})$. The source coordinates $\xi, \eta, \zeta$ are set a priori or are selected after solving the adjoint problem. We believe that the source acts for $0 \leq t \leq T$ continuously with constant intensity.

In the considered experiments, the function $F$ is approximated as follows

$$
\begin{array}{ll}
F=\frac{Q}{(\Delta x \Delta y \Delta z)} & \text { when } x=\xi, y=\eta, z=\zeta, \\
F=0 & \text { when } x \neq \xi, y \neq \eta, z \neq \zeta,
\end{array}
$$

where $\Delta x, \Delta y, \Delta z$ are the grid steps; $(\Delta x \Delta y \Delta z)$ is the box volume centered in the point $(\xi, \eta, \zeta)$. 
The function $p(x, y, z, t)$ is set in the following form

$$
\begin{array}{lr}
p=P=1 /\left(T \int_{x_{1}}^{x_{2}} \int_{y_{1}}^{y_{2}} \int_{0}^{H} d x d y d z\right) & \text { in the domain } \Omega, \\
p=0 & \text { out of the domain } \Omega,
\end{array}
$$

where $\Omega=\left\{x \in\left[x_{1}, x_{2}\right], y \in\left[y_{1}, y_{2}\right], z \in[0, H]\right\}$.

Thus, the functional $J$ represents the average concentration of the contamination entering the study zone during the time $T$ :

$$
J=P \int_{0}^{T} \int_{x_{1}}^{x_{2}} \int_{y_{1}}^{y_{2}} \int_{0}^{H} C d t d x d y d z
$$

According to the formula (18), setting the right-hand side of equation (14), further the "adjoint" concentration $C^{*}$ is calculated. Then, using the source function (17), it is written [17]:

$$
J=J(\xi, \eta, \zeta)=\int_{0}^{T} \int_{G} C^{*} F d G d t=Q \int_{0}^{T} C^{*}(\xi, \eta, \zeta, t) d t .
$$

The functional $J$, which is a function of coordinates, is calculated. According to the duality principle, the distribution of the average, in volume and in time, concentration of contamination $C$ in the conservation zone, depending on the coordinates and power of the source, is obtained.

Further, the functional $J$ will be called the dominant function. Based on criterion (15), the optimal source position (at a given power) is selected. Now, by specifying the source $F$ in the form of (17), the direct problem can be solved and the way that the contamination comes from it, actually spreads can be established.

Due to the shallowness of the considered region, the currents here are mainly determined by the wind. It is assumed that the wind is stable and does not change for several days, so the currents can be considered stationary. Then the contamination is transported by steady currents. They are calculated by threedimensional barotropic linear model [17] generalized to the case of taking into account Rayleigh friction (proportional to the current velocity) [17]. The model allows calculating three-dimensional currents by calculating the current velocity components using analytical formulas, since the solution reduces to a twodimensional problem for the integral function of the current. A description of the features of currents in bays and coastal currents is provided by grids with a fine step that is allowed in the model.

Numerical scheme. The admixture transfer problems, direct and adjoint, are solved numerically using finite-difference schemes described in [18, 19]. A grid with horizontal steps $\Delta x=39.5 \mathrm{~m}, \Delta y=55.5 \mathrm{~m}$ was applied in the calculations. An nonuniform partition into layers with horizons $Z_{k}$ equal to $0.1,0.9,3.1,6.9,13$, 1, 26.9, $43.1 \mathrm{~m}$ is taken vertically. The coefficients of the impurity horizontal and vertical diffusion were assumed constant: $\mu=10^{2} \mathrm{~cm}^{2} / \mathrm{s}, \kappa=0.1 \mathrm{~cm}^{2} / \mathrm{s}$. 
The coefficients of vertical viscosity and Rayleigh friction are also considered constant: $A=20 \mathrm{~cm}^{2} / \mathrm{s}, r=10^{-4} 1 / \mathrm{s}$. Coriolis parameter is $f=10^{-4} 1 / \mathrm{s}$.

Numerical experiments were carried out for the main wind directions: eastern, northeastern, northern, northwestern, southwestern, southern and southeastern. Western wind is excluded from consideration. We assume that the wind stress is horizontally uniform. Wind stress amplitude is assumed to be $1 \mathrm{~cm}^{2} / \mathrm{s}^{2}$, which corresponds to a wind velocity of $8 \mathrm{~m} / \mathrm{s}$.

Impurity transfer calculations in the direct and adjoint problems were performed for a time $T=2$ days with $\Delta t=1 \mathrm{~min}$ step. The stability of numerical scheme is ensured by the selection of a time step.

The currents in the upper layers $(0-5 \mathrm{~m})$ in all scenarios are directed almost downwind due to consideration of the Rayleigh friction. In the deep layers they rotate clockwise. And if in the coastal strip in the upper layers the currents are directed to the coast, then in the deep layers they are directed from the coast at the corresponding wind situation. Therefore, the contaminative impurity spreads along the coast only in the upper layers, in the underlying ones it enters the axial part of the bay and then gets into the open sea (at the corresponding wind situation).

Analysis of adjoint problem solution. As a result of solving the adjoint problem, we obtain the influence function $J$. We are to analyze its structure: we will consider how the average concentration of the impurity entering the conservation zone in two days depends on the source location. The power of source $Q$, for definiteness, was taken to be $10^{6} \mathrm{~g} / \mathrm{min}$ (ton per minute), i.e., over two days 2880 tons of contaminative impurity entered the sea. The magnitude of its concentration due to the linearity of the problem is directly proportional to the power of the source.

For the convenience of presenting the results, further we introduce the normalized influence function $J^{*}=J / J_{\max }$ (in percent), where $J_{\max }$ is the maximum value of the influence function obtained in a numerical experiment. In this calculation, $J_{\max }=0.211 \cdot 10^{-3} \mathrm{~g} / \mathrm{cm}^{3}$. The maximum possible amount of contaminative impurity that can enter the conservation zone $\left(10^{6} \mathrm{~m}^{3}\right.$ in volume $)$ in two days is 211 tons at the indicated source power.

The influence function in the conservation zone also depends on the depth of the source location. $J^{*}$ function distribution at different horizons at northern wind is presented in Fig. 2. $J^{*}$ isolines hereinafter are drawn with $5 \%$ step, the extreme isoline corresponds to $1 \%$ and in the shaded area $J^{*} \geq 5 \%$. For a pollution source located at any horizon on the isoline, for example, at $J^{*}=5 \%$, the concentration level of the contaminative impurity getting from this source into the region under consideration will be equal to $0.05 J_{\max }$. Thus, the restriction on the sanitary norm determines the selection of the source position. We emphasize that the influence function $J^{*}$ shows the effect of a source located on the same horizon at which the distribution is considered. 


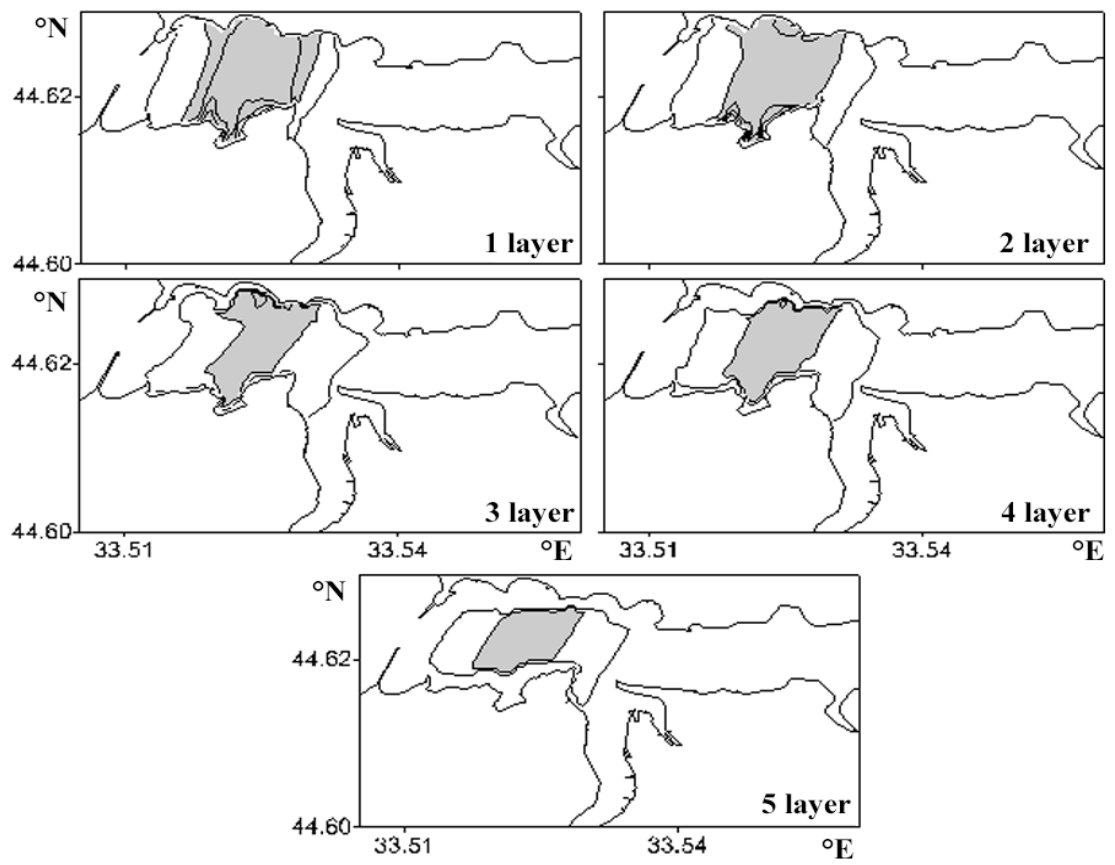

F i g. 2. Distribution of function $J^{*}$ on the horizons at the north wind

Note that the average concentration in $(J)$ layer can increase with depth depending on the layer thickness and variability of a current average velocity in it. The variability of the influence function by depth is illustrated in Fig. 3, which shows the dependence of the maximum value of function $J^{*}$ in the layers at a northern wind.

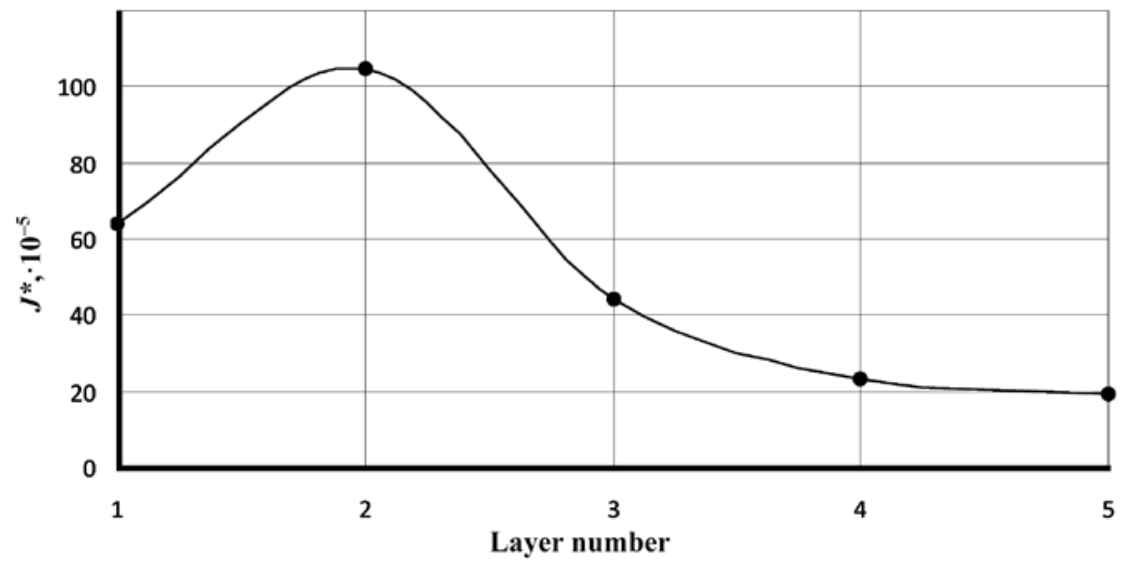

F i g. 3. Maximum value of function $J^{*}$ in the layers at the northern wind 
Experiments have shown that the most dangerous are the winds of the northern and eastern rhumbs. Industrial facilities, port facilities, stormwater and sewage from residential areas located on the Northern side of the Sevastopol Bay (in the areas marked gray in the figures) may cause damage to the recreational areas under consideration.

At eastern and southeastern wind, the main source of danger is the products of economic activity in the Yuzhnaya Bay. At the winds of the southern rhumbs, a pollution of the recreational zone is possible only by sources located within the nature protection zone itself. The western wind is not considered due to the fact that the open sea will be the effect zone at that.

Since the velocities in the upper layers (up to $25 \mathrm{~cm} / \mathrm{s}$ ) are much higher than in the lower layers $(2-3 \mathrm{~cm} / \mathrm{s})$ at a selected wind stress, the effect zones in the surface layers should be noticeably longer. In Fig. 4 the distribution of the function $J^{*}$ in the surface layer for different wind directions is shown.
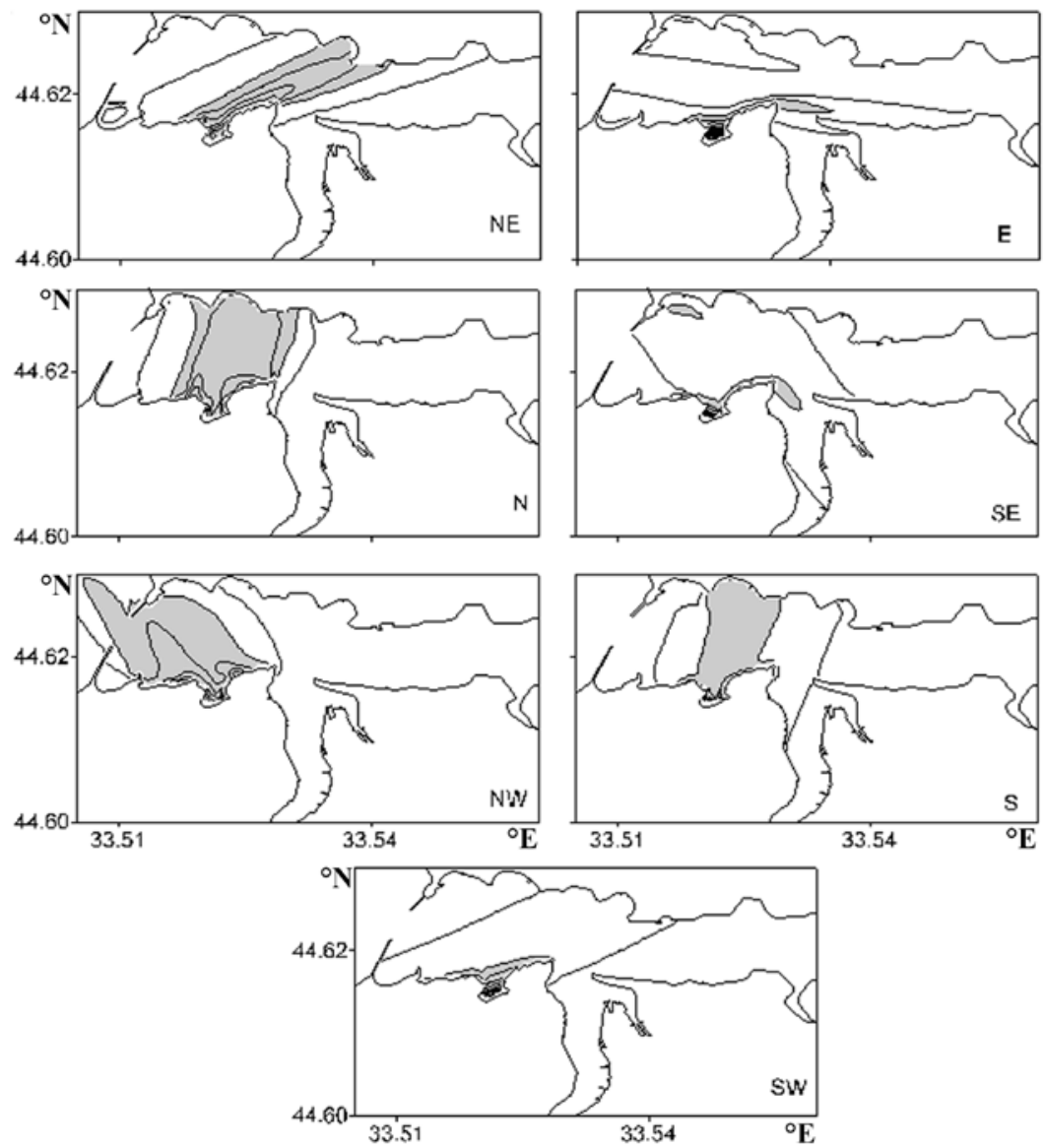

F i g. 4. Distribution of function $J^{*}$ in the surface layer at various winds 
Finally, if we bring together $J^{*}$ function distributions for all the main directions wind directions, we obtain a total distribution illustrating the location of potentially dangerous places for the selected preservation zone (Fig. 5).
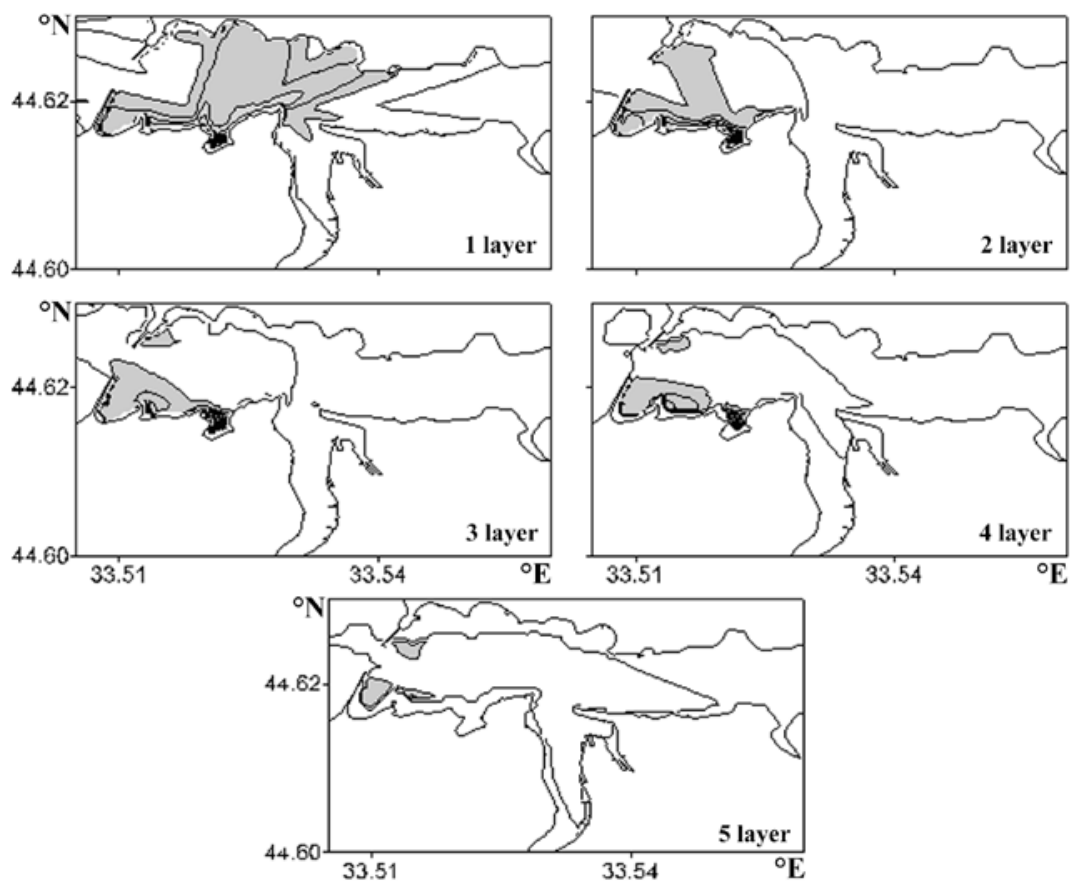

F i g. 5. Total distribution of function $J *$ in the layers

\section{Conclusion}

Based on the results of numerical modeling, the regions where the location of pollution sources will lead to a violation of sanitary norms in the considered preservation zone were identified.

According to the experiments, the winds of the northern and eastern rhumbs are the most dangerous ones, so the placement of industrial facilities, storm and sewage from residential areas on the Northern side of the Sevastopol Bay can harm the ecological condition of the region under consideration.

At the eastern and southeastern wind, the main source of danger is the products of economic activity in the Yuzhnaya Bay.

At the winds of the southern rhumbs, the sources located in the preservation zone can cause its pollution.

At the western wind, the open sea outside the bay will be the effect zone.

These conclusions are preliminary, since they were obtained for the situation of steady currents caused by a constant sufficiently strong wind. In reality, the duration and strength of the winds can be weaker and, accordingly, the currents can be less pronounced. The inhomogeneity of the wind above the bay can be affected by the relief of the coastal part surface which is pronounced, for example, 
in the Balaklava Bay. At high steep shores a shadow effect in certain wind directions may appear. This leads to the occurrence of coastal currents.

By setting the place and time of the impurity discharge and solving the direct problem, we can obtain information about its distribution in space and time. The solution of the adjoint problem provides information on the amount of impurities in the environmental area in a given perio

$\mathrm{d}$ of time at an arbitrary location of the source.

The main advantage of using the adjoint equation is efficiency: in order to determine the optimal location of pollution sources, taking into account sanitary standards for selected environmental objects, only one solution for the adjoint problem is required.

\section{REFERENCES}

1. Mukhametov, S.S. and Kondratev, S.I., 2017. Extreme Hydrochemical Parameters in the Sevastopol Bay Waters in February 2015 Arising from the Storm Runoff. Vestnik Moskovskogo Universiteta. Seria 5, Geografia, (6), pp. 9-17.

2. Belokopytov, V.N., Kubryakov, A.I. and Pryakhina, S.F., 2019. Modelling of Water Pollution Propagation in the Sevastopol Bay. Physical Oceanography, 26(1), pp. 3-12. doi:10.22449/1573-160X-2019-1-3-12

3. Gurov, K., Kotelyanets, E., Tikhonova, E. and Kondratev, S., 2019. Accumulations of Trace Metals in Bottom Sediments of the Sevastopol Bay (Black Sea) In: 19th International Multidisciplinary Scientific GeoConference SGEM 2019: Conference proceedings. Sofia, 2019. Vol. 19, iss. 3(1), pp. 649656. doi:10.5593/sgem2019/3.1/S15.083

4. Sovga, E.E., Mezentseva, I.V. and Kotelyanets, E.A., 2017. Assimilation Capacity of the Marine Shallow Water Ecosystems with Various Anthropogenic Impacts as the Estimation Method of Its Self-Purification Ability. Problems of Ecological Monitoring and Ecosystem Modelling, 28(4), pp. 38-51. doi:10.21513/0207-2564-2017-4-38-51 (in Russian).

5. Ivanov, V.A., Mezentceva, I.V., Sovga, E.E., Slepchuk, K.A. and Khmara, T.V., 2015. Assessment Self-Purification Ability of the Sevastopol Bay Ecosystem in Relation to Inorganic Forms of Nitrogen. Processes in GeoMedia, (2), pp. 55-65 (in Russian).

6. Slepchuk, K.A., Khmara, T.V. and Man’kovskaya, E.V., 2017. Comparative Assessment of the Trophic Level of the Sevastopol and Yuzhnaya Bays Using E-TRIX Index. Physical Oceanography, (5), pp. 60-70. doi:10.22449/1573-160X-2017-5-60-70

7. Gubanova, A.D., Garbazey, O.A., Popova, E.V., Altukhov D.A. and Mukhanov, V.S., 2019. Oithona davisae: Naturalization in the Black Sea, Interannual and Seasonal Dynamics, and effect on the Structure of the Planktonic Copepod Community. Oceanology, 59(6), pp. 912-919. https://doi.org/10.1134/S0001437019060079

8. Marchuk, G.I., 1986. Mathematical Models in Environmental Problems. Amsterdam: Elsevier Science Publishers B.V., 216 p.

9. Zhmenya, E.S. and Buzalo, N.S., 2018. Sensitivity of Biological Sewage Disposal Efficiency Functional to Parameters of Biogen Concentration Dynamics Model. Vestnik of Don State Technical University, 18(1), pp. 85-91. doi:10.23947/1992-59802018-18-1-85-91 
10. Marchuk, G.I. and Penenko, V.V., 1979. Application of Optimization Methods to the Problem of Mathematical Simulation of Atmospheric Processes and Environment. In: G.I. Marchuk, ed., 1979. Modelling and Optimization of Complex System. Berlin: Springer, pp. 240-252. https://doi.org/10.1007/BFb0004167

11. Buzalo, N.S. and Nikiforov, A.N., 2013. Adjoint Equations in Control Problems of Non-Conservative Admixture Concentration. Izvestiya SFedU. Engineering Sciences, 4(141), pp. 203-209 (in Russian).

12. Shutyaev, V.P., Le Dimet, F.-X., Agoshkov, V.I. and Parmuzin, E.I., 2015. Sensitivity of Functionals in Problems of Variational Assimilation of Observational Data. Izvestiya, Atmospheric and Oceanic Physics, 51(3), pp. 342-350. doi:10.1134/S0001433815030111

13. Dymova, O.A., Kochergin, V.S. and Kochergin, S.V., 2018. Identifying the Location of a Possible Source Pollution in the Waters of the Heraclea Peninsula Based on the Method of Adjoint Equations. Ecological Bulletin of Research Centers of the Black Sea Economic Cooperation, 15(3), pp. 72-77. https://doi.org/10.31429/vestnik-15-3$72-77$

14. Ivanov, V.A., Cherkesov, L.V. and Shul'ga, T.Y., 2012. Investigation of Effects of Spatially and Temporally Variable Wind on Currents, Surges, and Admixture Spread in the Sea of Azov. Russian Meteorology and Hydrology, 37(8), pp. 553-559. doi:10.3103/S1068373912080079

15. Ivanov, V.A., Cherkesov, L.V. and Shul'ga, T.Y., 2014. Dynamic Processes and Their Influence on the Transformation of the Passive Admixture in the Sea of Azov. Oceanology, 54(4), pp. 426-434. doi:10.1134/S0001437014030023

16. Kochergin, V.S., Kochergin, S.V. and Stanichny, S.V, 2017. Identification of Pollution Sources in the Sea of Azov Using the Adjoint Equation Method. Sovremennye Problemy Distantsionnogo Zondirovaniya Zemli iz Kosmosa, 14(1), pp. 50-57. doi:10.21046/2070-7401-2017-14-1-50-57 (in Russian)

17. Ruabtzev, Yu.N. and Shapiro, N.B., 2007. Optimization the Source of Water Pollution locations on Sevastopol Coastal Waters Taking into Account the Damage Minimization for Recreational Zone. In: MHI, 2007. Ekologicheskaya Bezopasnost' Pribrezhnykh i Shel'fovykh Zon i Kompleksnoe Ispol'zovanie Resursov Shel'fa [Ecological Safety of Coastal and Shelf Zones and Comprehensive Use of Shelf Resources]. Sevastopol: ECOSI-Gidrofizika. Iss. 15, pp. 280-298 (in Russian).

18. Shapiro, N.B., 2006. Modeling of the Currents on the Seaside nearby Seavastopol City. In: MHI, 2006. Ekologicheskaya Bezopasnost' Pribrezhnykh i Shel'fovykh Zon i Kompleksnoe Ispol'zovanie Resursov Shel'fa [Ecological Safety of Coastal and Shelf Zones and Comprehensive Use of Shelf Resources]. Sevastopol: ECOSI-Gidrofizika. Iss. 14, pp. 119-134 (in Russian).

19. Mikhailova, E.N., Shapiro, N.B. and Yushchenko, S.A., 1999. Modeling of Passive Admixture Propagation in Sevastopol Bays. Morskoy Gidrofizicheskiy Zhurnal, (3), pp. 29-42 (in Russian).

About the authors:

Yury N. Ryabtsev, Research Associate, Marine Hydrophysical Institute of RAS (2 Kapitanskaya St., Sevastopol, 299011, Russian Federation), ORCID ID: 0000-0002-96829969, ruab@mail.ru 
Marina V. Tsyganova, Junior Research Assocate, Marine Hydrophysical Institute of RAS (2 Kapitanskaya St., Sevastopol, 299011, Russian Federation), ORCID ID: 00000003-2398-1756, ResearcherID S-5426-2018 m.tsyganova@mhi-ras.ru

Contribution of the co-authors:

Yury N. Ryabtsev - formulation and statement of the problem; development of a mathematical model; selection and justification of numerical methods for solving equations; correction of the mathematical model and calculations; analysis and synthesis of research results

Marina V. Tsyganova - analysis of materials in domestic and foreign sources according to research methods; literature review on research; carrying out calculations; revision of the text; plotting; writing of annotations; visualization / presentation of data in text

All the authors have read and approved the final manuscript.

The authors declare that they have no conflict of interest. 